\title{
Editorial
}

\section{Participação internacional e gênero nas autorias da RAP}

\section{Alketa Peci ${ }^{1}$}

1 Fundação Getulio Vargas/Escola Brasileira de Administração Pública e de Empresas, Rio de Janeiro/RJ - Brasil

O quinto número da RAP de 2019 nos brinda com cinco artigos internacionais, demonstrando que a estratégia de internacionalização da revista alcança consistentes resultados. São artigos representativos de países como Portugal, Chile, Colômbia e Paraguai. Rosa Monteiro e colegas analisam as questões de gênero em organizações públicas, verificando se, em contextos organizacionais altamente masculinizados, a estereotipia de gênero tende a ser mais acentuada. Marcelo Sili aborda os diversos estilos e lógicas de ação territorial no contexto dos municípios do Paraguai. Antoine Maillet e Sebastián Carrasco incluem na análise da regulação o conceito do poder de negócio dos atores privados, apontando que as fragilidades de regulação do sistema de transporte público em Santiago devem-se à incapacidade, por parte das autoridades públicas, de impor suas preferências. Ana Carina Azevedo faz uma análise histórica do processo de reforma da administração pública em Portugal tendo por base vários fatores internacionais e pressões de desenvolvimento econômico e social nacionais. Por fim, Maria Alejandra Gutiérrez Fonseca e Alejandro Balanzó Guzmán tratam dos desafios do Sistema Geral de Direitos na transformação do ambiente de gestão territorial na Colômbia.

Os outros artigos que apreciam o contexto brasileiro abordam dois temas transversais: as parcerias entre os governos e as organizações da sociedade civil; e avaliações do Programa Bolsa Família. Patricia Mendonca, Anny Medeiros e Edgilson Tavares de Araujo analisam os modelos de parceria comparando as políticas adotadas em três setores, AIDS, assistência social e cultura no Brasil, e elaboram importantes contribuições em termos de aperfeiçoamento de políticas públicas. Lindsay Sant Anna e colegas alinham conceitualmente a governança colaborativa com a teoria de ação comunicativa para aproximar as práticas de colaboração comunicativa entre o Estado e a sociedade.

Por fim, os conjuntos de três trabalhos que analisam por várias dimensões o Programa Bolsa Família juntam-se a outros já publicados na RAP ao longo dos últimos anos e demonstram, por si, a relevância deste programa público. Carlos Barnosa Correa Junior, Leonardo Nelmi Trevisan e Cristina Helena Pinto de Mello examinam os impactos do programa no mercado de trabalho formal dos municípios brasileiros, indicando associação positiva. Marcelo Neri e Manuel Camillo Osorio contribuem com mais uma avaliação do programa, relacionando o Bolsa Família ao tempo na escola e às motivações estudantis. Por fim, Cristiane Kerches da Silva Leite, Francisco Fonseca e Bruna Holanda em outro espectro de análise, focam nas imagens e narrativas acerca do Bolsa Família veiculadas pela grande imprensa. Os autores formulam as categorias de assistencialismo, insuficiência, marketing eleitoral e populismo e concluem que há desconexão entre estas narrativas criadas pela grande imprensa e um sentimento público favorável ao programa e seus impactos, como demonstrado por várias avaliações 
do programa (entre os quais, juntam-se os dois artigos publicados neste número da Revista).

Por fim, destaco a expressiva (porém não majoritária) participação de autoras neste número da revista. Espera-se, pelo aprendizado com um dos artigos deste número, que a participação no mercado de trabalho dos homens com níveis de instrução mais elevados, como é o caso da academia, articulese com atitudes mais igualitaristas. Entretanto, a academia não apenas apresenta-se, ainda, como um contexto expressivamente masculinizado, como também os obstáculos a serem vencidos pelas pesquisadoras são cotidianos. Outros fatores influenciam as práticas diárias de exclusão da diversidade na academia e estes demandam nossa contínua reflexão.

Desejo a todos uma boa leitura!

Alketa Peci

Editora-chefe

\section{Alketa Peci}

https://orcid.org/0000-0002-0488-1744

Doutora em Administração e professora associada da Escola Brasileira de Administração Pública e de Empresas da Fundação Getulio Vargas; Editora-chefe da Revista de Administração Pública (RAP). E-mail: alketa@fgv.br 